\title{
Radiosurgery in Comparison with Surgery for Treatment of Neurofibromatosis Type 2 (NF-2) Associated Acoustic Neuroma (AN)
}

\author{
Selcuk Demiral, Murat Beyzadeoglu, Ferrat Dincoglan, Omer Sager*, Hakan Gamsiz, Bora \\ Uysal, Fatih Ozcan, Onurhan Colak and Bahar Dirican \\ Department of Radiation Oncology, University of Health Sciences, Gulhane Medical Faculty, Ankara, Turkey
}

*Corresponding author: Omer Sager, Department of Radiation Oncology, University of Health Sciences, Gulhane Medical Faculty, Ankara, Turkey

\begin{tabular}{l}
\hline ARTICLE INFO \\
\hline Received: May 11, 2020 \\
Published: May 21, 2020 \\
\hline Citation: Selcuk D, Murat B, Ferrat D, Omer \\
S, Hakan G, et al., Radiosurgery in Compar- \\
ison with Surgery for Treatment of Neu- \\
rofibromatosis Type 2 (NF-2) Associated \\
Acoustic Neuroma (AN). Biomed J Sci \& \\
Tech Res 27(5)-2020.BJSTR. MS.ID.004556.
\end{tabular}

Abbreviations: AN: Acoustic Neuroma; CNS: Central Nervous System; VGEF: Vascular Endothelial Growth Factor; EGFR: Epidermal Growth Factor Receptor; mTOR: Mammalian Target of Rapamycin; SRS: Stereotactic Radiosurgery; FSRT: Fractionated Stereotactic Radiotherapy; HFSRT: Hypofractionated Stereotactic Radiotherapy; SABR: Stereotactic Ablative Body Radiotherapy

\begin{abstract}
Acoustic neuroma (AN), also known as acoustic neurinoma or vestibular schwannoma is a primary intracranial tumor derived from Schwann cells of the myelin sheath surrounding the 8th cranial nerve. AN is typically located in the internal auricular canal or at the cerebellopontine angle in the vicinity of critical neurovascular structures, and compression due to the mass effect may lead to associated symptoms in affected patients with potential to deteriorate quality of life. NF-2 refers to a neurocutaneous tumor predisposition syndrome with autosomal dominant inheritance pattern, and presence of bilateral AN is considered as a hallmark. Management of NF-2 associated AN warrants thorough consideration of individual patient characteristics given that different cranial nerves may be involved in these patients. Advances in the discipline of radiation oncology coupled with improvements in neuroimaging have expanded the applications of radiosurgery to be used more frequently as a primary treatment modality for many intracranial disorders and tumors. In the context of AN management, safety and efficacy of radiosurgery is being increasingly evident with accumulating data from several centers worldwide. Nevertheless, utility of radiosurgery in treating NF-2 associated AN is less clear with less available data compared to unilateral sporadic AN. Both surgery and radiosurgery have their unique advantages and disadvantages in management. Radiosurgery has the inherent advantage of being a noninvasive treatment modality with improved normal tissue sparing capability due to steep dose gradients around the target volume. A direct comparison between surgery and radiosurgery is confounded by several factors. Herein, we provide a concise review of radiosurgery in comparison with surgery for treatment of neurofibromatosis type 2 (NF-2) associated AN.
\end{abstract}

Keywords: Neurofibromatosis Type 2 (NF-2); Acoustic Neuroma (AN); Radiosurgery

\section{Introduction}

Acoustic neuroma (AN), also known as acoustic neurinoma or vestibular schwannoma is a primary intracranial tumor derived from Schwann cells of the myelin sheath surrounding the 8th cranial nerve which may be observed or treated by surgery, radiosurgery, or with a combined modality approach depending on individual patient and tumor characteristics [1-5]. The incidence of these benign and typically slow growing tumors is in an increasing trend given the substantial improvements in neuroimaging techniques and aging of the population [6-8]. Despite the indolent disease course in an overwhelming majority of patients, symptomatology may include hearing impairment, tinnitus, vertigo, dizziness, headache, incoordination or instability, gait ataxia, cranial nerve symptoms due to involvement of facial and trigeminal nerves, facial dysesthesia or spasms, dysphagia, dysarthria, cerebellar seizures, symptoms of increased intracranial pressure and respiratory distress in some of the affected patients [1-5]. AN is typically located in the internal auricular canal or at the cerebellopontine angle in the vicinity of critical neurovascular structures, and compression 
due to the mass effect may lead to associated symptoms in affected patients with potential to deteriorate quality of life. Several factors such as lesion size, location and association with critical structures, symptomatology, age, patient preferences, and logistical issues are taken into account in decision making for management of AN. Herein, we provide a concise review of radiosurgery in comparison with surgery for treatment of neurofibromatosis type 2 (NF-2) associated AN.

\section{Literature Review of Radiosurgery in Comparison with Surgery for Treatment of NF-2 AN}

NF-2 refers to a neurocutaneous tumor predisposition syndrome with autosomal dominant inheritance pattern which is specified by multiple neoplasms and several central nervous system (CNS) manifestations [9-11]. There is mutation of the tumor supressor gene NF-2 located on chromosome 22, and presence of bilateral AN is considered as a hallmark [9-11]. A variety of molecularly targeted therapies focused on inhibition of angiogenesis, vascular endothelial growth factor (VGEF), epidermal growth factor receptor (EGFR), mammalian target of rapamycin (mTOR), tyrosine kinases and several other targets have been utilized for management of NF-2 [12-15]. Management of NF-2 associated AN warrants thorough consideration of individual patient characteristics given that different cranial nerves may be involved in these patients [16]. Most frequently involved cranial nerves include the facial and vestibulocochlear nerves, and management without further deterioration of quality of life is an important aspect in decision making for treatment. Radiosurgical management with stereotactic radiosurgery (SRS), fractionated stereotactic radiotherapy (FSRT), hypofractionated stereotactic radiotherapy (HFSRT), and Stereotactic Ablative Body Radiotherapy (SABR) serves as a viable treatment approach for focused and accurate irradiation of many CNS disorders and tumors throughout the human body with encouraging therapeutic outcomes [17-53]. Rationale for radiosurgery is to provide focused and ablative treatment through vascular endothelial damage, and well defined and relatively smaller targets are well suited for radiosurgical applications given the high doses delivered in single or a few fractions under robust immobilization and image guidance.

Steeper dose gradients around the target allows for improved normal tissue sparing, however, accurate target localization by use of advanced neuroimaging capabilities is an important aspect of radiosurgical management to avoid geographical misses [1753]. There are currently different platforms for radiosurgery which all provide excellent delivery of focused irradiation to achieve satisfactory local control rates for AN. In the context of NF-2 associated AN, several studies have addressed the utility of radiosurgery for management [54-62]. In the study by Mathieu et al. assessing the outcomes of radiosurgery for NF-2 associated AN, 74 lesions of 62 patients were treated [54]. At a median follow up duration of 53 months, reported rates of actuarial local control at 5, 10, and 15 years was 85\%, 81\%, and 81\%, respectively [54]. The authors concluded that selected patients with NF-2 associated AN could be considered for primary radiosurgical management given the safety and efficacy of radiosurgery for treatment of these patients [54]. In the study by Meijer et al. addressing management of bilateral NF-2 associated AN with linear accelerator based radiosurgery, local control was provided for the 20 evaluable patients without treatment related trigeminal or facial nerve toxicity at a median follow up duration of 51 months [55]. The authors concluded that excellent local control rates were achieved with linear accelerator based radiosurgery for NF-2 associated AN [55]. In the study by Rowe et al., the authors suggested radiosurgery as a valuable minimally invasive therapeutic option for management of selected patients with NF-2 associated AN [56].

In the study by Phi et al. assessing the radiologically proven local control rates after radiosurgery of NF-2 associated AN, 36 lesions in 30 patients were analyzed with a median clinical follow up duration exceeding 4 years and median radiological follow up duration exceeding 3 years [57]. Actuarial tumor control rates at 1, 2 and 5 years was $81 \%, 74 \%$, and $66 \%$, respectively [57]. The authors concluded that radiosurgery could be included in management options for patients with NF-2 associated AN [57]. In the study by Sun and Liu evaluating long term clinical outcomes and the role of radiosurgery for NF-2 associated $\mathrm{AN}$, total rate of tumor control for bilateral NF-2 associated AN was 84\% [58]. The authors concluded that radiosurgery provided long term tumor control for small to medium sized lesions and other types of tumors despite the fact that unilateral sporadic AN had better response to radiosurgery compared to NF-2 associated AN [58]. In the study by Mallory et al. assessing optimal radiosurgery dose parameters and long term outcomes of radiosurgery for NF-2 associated AN, 32 lesions in 26 patients were treated [59]. At a median follow up duration of 7.6 years, no growth was observed in 27 lesions (84\%) out of the total 32 lesions [59]. The authors concluded that higher marginal doses than frequently prescribed for sporadic AN radiosurgery were found to be in association with increased tumor control for NF-2 associated AN [59]. Also, the advantage of radiosurgery which is allowing an anatomically preserved cochlear nerve was emphasized along with the opportunity of hearing rehabilitation with cochlear implantation [59]. In the study by Kruyt et al., actuarial tumor control rates were $98 \%, 89 \%, 87 \%$, and $87 \%$ after $1,3,5$, and 8 years, respectively for NF-2 associated AN [60]. The authors concluded that the use of low margin doses for treating growing NF-2 associated AN with modern radiosurgical techniques yielded good long term tumor control rates and radiosurgery could serve as a valid treatment option for particularly small to medium size NF-2 associated AN [60].

In the study by Shinya et al. evaluating radiosurgical outcomes for AN, 30 lesions in 25 patients with NF-2 associated AN were analyzed with a mean follow up duration exceeding 10 years [61]. The authors concluded that excellent long term tumor control 
coupled with the inherent advantage of being a noninvasive treatment modality rendered radiosurgery a favorable therapeutic option for small to medium sized NF-2 associated AN [61]. In the systematic review by Shinya et al. comparatively assessing radiosurgery versus surgery for NF-2 associated AN management, major databases were queried by using relevant search terms and retrospective studies focusing on outcomes of patients undergoing either radiosurgery or surgery for NF-2 associated AN were included with exclusion of single patient case reports [62]. A total of 974 patients 485 of whom received radiosurgery and 489 of whom underwent surgery were identified [62]. Mean 5 year local control rate was $75.1 \%$ for radiosurgery with the mean recurrence rate for surgery being $8.1 \%$ [62]. Hearing preservation rates were higher after surgery compared to radiosurgery, and facial nerve preservation rates were higher after radiosurgery compared to surgery [62]. Despite higher hearing preservation rates in surgery cohorts, radiosurgery was found to achieve high local control rates with significantly lower facial nerve complications [62]. The authors commented that selected patients with NF-2 associated AN could benefit more from radiosurgery than surgery [62].

\section{Conclusion and Future Perspectives}

Recent years have witnessed many improvements in the radiation oncology discipline including, but not limited to, contemporary irradiation technologies such as Intensity Modulated Radiation Therapy (IMRT), Image Guided Radiation Therapy (IGRT), Breathing Adapted Radiation Therapy (BART), Adaptive Radiation Therapy (ART) as well as radiosurgical applications such as SRS, FSRT, HFST, and SABR [17-53,63-71]. These advances coupled with improvements in neuroimaging have expanded the applications of radiosurgery to be used more frequently as a primary treatment modality for many intracranial disorders and tumors. In the context of AN management, safety and efficacy of radiosurgery is being increasingly evident with accumulating data from several centers worldwide. Nevertheless, utility of radiosurgery in treating NF-2 associated AN is less clear with less available data compared to unilateral sporadic AN. Both surgery and radiosurgery have their unique advantages and disadvantages in management. Surgical techniques are in evolution towards improved sparing of functionality and quality of life although there is room for further improvements. Radiosurgery has the inherent advantage of being a noninvasive treatment modality with improved normal tissue sparing capability due to steep dose gradients around the target volume. A direct comparison between surgery and radiosurgery is confounded by several factors. In this context, future trials are needed to shed light on optimal management of NF-2 associated AN.

\section{References}

1. Hardy DG (2000) Acoustic neuroma surgery as an interdisciplinary approach. J Neurol Neurosurg Psychiatry 69(2): 147-148.
2. Pinna MH, Bento RF, Neto RV (2012) Vestibular schwannoma: 825 cases from a 25-year experience. Int Arch Otorhinolaryngol 16(4): 466-475.

3. Pandrangi VC, Han AY, Alonso JE, Peng KA, St John MA (2020) An Update on Epidemiology and Management Trends of Vestibular Schwannomas. Otol Neurotol 41(3): 411-417.

4. Starnoni D, Daniel RT, Tuleasca C, George M, Levivier M, et al. (2018) Systematic review and meta-analysis of the technique of subtotal resection and stereotactic radiosurgery for large vestibular schwannomas: A "nerve-centered" approach. Neurosurg Focus 44(3): E4.

5. Strickland BA, Ravina K, Rennert RC, Jackanich A, Aaron K, et al. (2020) Intentional Subtotal Resection of Vestibular Schwannoma: A Reexamination. J Neurol Surg B Skull Base 81(2): 136-141.

6. Mirz F, Jørgensen B, Fiirgaard B, Lundorf E, Pedersen CB (1999) Investigations into the natural history of vestibular schwannomas. Clin Otolaryngol Allied Sci 24(1): 13-18.

7. Propp JM, McCarthy BJ, Davis FG, Preston Martin S (2006) Descriptive epidemiology of vestibular schwannomas. Neuro Oncol 8(1): 1-11.

8. Stangerup SE, Caye Thomasen P (2012) Epidemiology and natural history of vestibular schwannomas. Otolaryngol Clin North Am 45(2): 257-268.

9. Seizinger BR, Martuza RL, Gusella JF (1986) Loss of genes on chromosome 22 in tumorigenesis of human acoustic neuroma. Nature 322(6080): 644-647.

10. Evans DG (2015) Neurofibromatosis type 2. Handb Clin Neurol 132: 87 96.

11. Coy S, Rashid R, Stemmer Rachamimov A, Santagata S (2020) An update on the CNS manifestations of neurofibromatosis type 2. Acta Neuropathol 139(4): 643-665.

12. Subbiah V, Slopis J, Hong DS, Ketonen LM, Hamilton J, et al. (2012) Treatment of patients with advanced neurofibromatosis type 2 with novel molecularly targeted therapies: from bench to bedside. J Clin Oncol 30(5): e64-68.

13. Goutagny S, Giovannini M, Kalamarides M (2017) A 4-year phase II study of everolimus in NF2 patients with growing vestibular schwannomas. J Neurooncol 133(2): 443-445.

14. Goutagny S, Kalamarides M (2018) Medical treatment in neurofibromatosis type 2. Review of the literature and presentation of clinical reports. Neurochirurgie 64(5): 370-374.

15. Plotkin SR, Duda DG, Muzikansky A, Allen J, Blakeley J, et al. (2019) Multicenter, Prospective, Phase II and Biomarker Study of High-Dose Bevacizumab as Induction Therapy in Patients With Neurofibromatosis Type 2 and Progressive Vestibular Schwannoma. J Clin Oncol 37(35): 3446-3454.

16. Samii M, Matthies C, Tatagiba M (1997) Management of vestibular schwannomas (acoustic neuromas): auditory and facial nerve function after resection of 120 vestibular schwannomas in patients with neurofibromatosis 2. Neurosurgery 40(4): 696-705; discussion 705706.

17. Dincoglan F, Sager O, Uysal B, Demiral S, Gamsiz H, et al. (2019) Evaluation of hypofractionated stereotactic radiotherapy (HFSRT) to the resection cavity after surgical resection of brain metastases: A single center experience. Indian J Cancer 56(3): 202-206.

18. Demiral S, Dincoglan F, Sager O, Uysal B, Gamsiz H, et al. (2018) Contemporary Management of Meningiomas with Radiosurgery. Int J Radiol Imaging Technol 4(2): 1-8.

19. Sager O, Dincoglan F, Demiral S, Uysal B, Gamsiz H, et al. (2018) Radiation Therapy (RT) for Diffuse Intrinsic Pontine Glioma (DIPG) in Children. Arch Can Res 6(3): 14. 
20. Dincoglan F, Sager O, Demiral S, Uysal B, Gamsiz H, et al. (2017) Radiosurgery for recurrent glioblastoma: A review article. Neurol DisordTherap 1(4): 1-5.

21. Demiral S, Dincoglan F, Sager O, Gamsiz H, Uysal B, et al. (2016) Hypofractionated stereotactic radiotherapy (HFSRT) for who grade anterior clinoid meningiomas (ACM). Jpn J Radiol 34(11): 730-737.

22. Dincoglan F, Beyzadeoglu M, Sager O, Demiral S, Gamsiz H, et al (2015) Management of patients with recurrent glioblastoma using hypofractionated stereotactic radiotherapy. Tumori 101(2): 179-184.

23. Gamsiz H, Beyzadeoglu M, Sager O, Demiral S, Dincoglan F, et al. (2015) Evaluation of stereotactic body radiation therapy in the management of adrenal metastases from non-small cell lung cancer. Tumori 101(1): 98103.

24. Demiral S, Beyzadeoglu M, Sager O, Dincoglan F, Gamsiz H, et al. (2014) Evaluation of linear accelerator (linac)-based stereotactic radiosurgery (SRS) for the treatment of craniopharyngiomas. UHOD - Uluslararas Hematoloji-Onkoloji Dergisi 24(2): 123-129.

25. Dincoglan F, Sager O, Gamsiz H, Uysal B, Demiral S, et al. (2014) Management of patients with $\geq 4$ brain metastases using stereotactic radiosurgery boost after whole brain irradiation. Tumori 100(3): 302306.

26. Gamsiz H, Beyzadeoglu M, Sager O, Dincoglan F, Demiral S, et al. (2014) Management of pulmonary oligometastases by stereotactic body radiotherapy. Tumori $100(2): 179-183$.

27. Sager O, Dincoglan F, Beyzadeoglu M (2015) Stereotactic radiosurgery of glomus jugulare tumors: Current concepts, recent advances and future perspectives. CNS Oncol 4(2): 105-114.

28. Sager O, Beyzadeoglu M, Dincoglan F, Gamsiz H, Demiral S, et al. (2014) Evaluation of linear accelerator-based stereotactic radiosurgery in the management of glomus jugulare tumors. Tumori 100(2): 184-188.

29. Sager O, Beyzadeoglu M, Dincoglan F, Uysal B, Gamsiz H, et al. (2014) Evaluation of linear accelerator (LINAC)-based stereotactic radiosurgery (SRS) for cerebral cavernous malformations: A 15-year single-center experience. Ann Saudi Med 34(1): 54-58.

30. Demiral S, Beyzadeoglu M, Uysal B, Oysul K, Kahya YE, et al. (2013) Evaluation of stereotactic body radiotherapy (SBRT) boost in the management of endometrial cancer. Neoplasma 60(3): 322-327.

31. Sager O, Beyzadeoglu M, Dincoglan F, Demiral S, Uysal B, et al. (2013) Management of vestibular schwannomas with linear accelerator-based stereotactic radiosurgery: a single center experience. Tumori 99(5): 617-622.

32. Dincoglan F, Beyzadeoglu M, Sager O, Uysal B, Demiral S, et al. (2013) Evaluation of linear accelerator-based stereotactic radiosurgery in the management of meningiomas: A single center experience. J BUON 18(3): 717-722.

33. Dincoglan F, Sager O, Gamsiz H, Uysal B, Demiral S, et al. (2012) Stereotactic radiosurgery for intracranial tumors: A single center experience. Gulhane Med J 54(3): 190-198.

34. Dincoglan F, Sager O, Gamsiz H, Demiral S, Uysal B, et al. (2012) Management of arteriovenous malformations by stereotactic radiosurgery: A single center experience. UHOD - Uluslararasi Hematoloji-Onkoloji Dergisi 22(2): 107-112.

35. Dincoglan F, Beyzadeoglu M, Sager O, Oysul K, Sirin S, et al. (2012) Imageguided positioning in intracranial non-invasive stereotactic radiosurgery for the treatment of brain metastasis. Tumori 98(5): 630635.

36. Sirin S, Oysul K, Surenkok S, Sager O, Dincoglan F, et al. (2011) Linear accelerator-based stereotactic radiosurgery in recurrent glioblastoma: A single center experience. Vojnosanit Pregl 68(11): 961-966.

37. Dincoglan F, Sager O, Demiral S, Gamsiz H, Uysal B, et al. (2019) Fractionated stereotactic radiosurgery for locally recurrent brain metastases after failed stereotactic radiosurgery. Indian J Cancer 56(2): 151-156.
38. Surenkok S, Sager O, Dincoglan F, Gamsiz H, Demiral S, et al. (2012) Stereotactic radiosurgery in pituitary adenomas: A single center experience. UHOD - Uluslararasi Hematoloji-Onkoloji Dergisi 22(4): 255-260.

39. Dincoglan F, Sager O, Demiral S, Beyzadeoglu M (2019) Incorporation of Multimodality Imaging in Radiosurgery Planning for Craniopharyngiomas: An Original Article. SAJ Cancer Sci 6: 103.

40. Demiral S, Sager O, Dincoglan F, Beyzadeoglu M (2019) Assessment of Computed Tomography (CT) And Magnetic Resonance Imaging (MRI) Based Radiosurgery Treatment Planning for Pituitary Adenomas. Canc Therapy \& Oncol Int J 13(2): 555857.

41. Beyzadeoglu M, Sager O, Dincoglan F, Demiral S (2019) Evaluation of Target Definition for Stereotactic Reirradiation of Recurrent Glioblastoma. Arch Can Res 7(1): 3.

42. Sager O, Dincoglan F, Demiral S, Beyzadeoglu M (2019) Evaluation of Radiosurgery Target Volume Determination for Meningiomas Based on Computed Tomography (CT) And Magnetic Resonance Imaging (MRI). Cancer Sci Res Open Access 5(2): 1-4.

43. Dincoglan F, Sager O, Demiral S, Beyzadeoglu M (2019) Multimodality Imaging for Radiosurgical Management of Arteriovenous Malformations. Asian Journal of Pharmacy, Nursing and Medical Sciences 7(1): 7-12.

44. Demiral S, Sager 0, Dincoglan F, Beyzadeoglu M (2019) Assessment of target definition based on Multimodality imaging for radiosurgical Management of glomus jugulare tumors (GJTs). Canc Therapy \& Oncol Int J 15(2): 555909.

45. Sager O, Dincoglan F, Demiral S, Gamsiz H, Uysal B, et al. (2019) Utility of Magnetic Resonance Imaging (Imaging) in Target Volume Definition for Radiosurgery of Acoustic Neuromas. Int J Cancer Clin Res 6(3): 119.

46. Sager O, Dincoglan F, Demiral S, Gamsiz H, Uysal B, et al. (2019) Evaluation of the Impact of Magnetic Resonance Imaging (MRI) on Gross Tumor Volume (GTV) Definition for Radiation Treatment Planning (RTP) of Inoperable High Grade Gliomas (HGGs). Concepts in Magnetic Resonance Part A 2019: 4282754.

47. Demiral S, Sager O, Dincoglan F, Uysal B, Gamsiz H, et al. (2018) Evaluation of Target Volume Determination for Single Session Stereotactic Radiosurgery (SRS) of Brain Metastases. Canc Therapy \& Oncol Int J 12(5): 555848.

48. Sager O, Demiral S, Dincoglan F, Beyzadeoglu M (2020) Target Volume Definition for Stereotactic Radiosurgery (SRS) Of Cerebral Cavernous Malformations (CCMs). Canc Therapy \& Oncol Int J 15(4): 555917.

49. Dincoglan F, Demiral S, Sager O, Beyzadeoglu M (2020) Utility of Multimodality Imaging Based Target Volume Definition for Radiosurgery of Trigeminal Neuralgia: An Original Article. Biomed J Sci \& Tech Res 26(2): 19728-19732.

50. Beyzadeoglu M, Dincoglan F, Demiral S, Sager O (2020) Target Volume Determination for Precise Radiation Therapy (RT) of Central Neurocytoma: An Original Article. International Journal of Research Studies in Medical and Health Sciences 5(3): 29-34.

51. Demiral S, Beyzadeoglu M, Dincoglan F, Sager O (2020) Assessment of Target Volume Definition for Radiosurgery of Atypical Meningiomas with Multimodality Imaging. Journal of Hematology and Oncology Research 3(4): 14-21

52. Dincoglan F, Beyzadeoglu M, Sager O, Demiral S, Uysal B, et al. (2020) A Concise Review of Irradiation for Temporal Bone Chemodectomas (TBC). Arch Otolaryngol Rhinol 6(2): 016-020.

53. Dincoglan F, Beyzadeoglu M, Demiral S, Sager O (2020) Assessment of Treatment Volume Definition for Irradiation of Spinal Ependymomas: an Original Article. ARC Journal of Cancer Science 6(1): 1-6.

54. Mathieu D, Kondziolka D, Flickinger JC, Niranjan A, Williamson R, et al. (2007) Stereotactic radiosurgery for vestibular schwannomas in patients with neurofibromatosis type 2: an analysis of tumor control, complications, and hearing preservation rates. Neurosurgery 60(3): 460-468; discussion 468-470 
55. Meijer OW, Vandertop WP, Lagerwaard FJ, Slotman BJ (2008) Linear accelerator-based stereotactic radiosurgery for bilateral vestibular schwannomas in patients with neurofibromatosis type 2. Neurosurgery 62(5): A37-42; discussion A42-43

56. Rowe J, Radatz M, Kemeny A (2008) Radiosurgery for type II neurofibromatosis. Prog Neurol Surg 21: 176-182.

57. Phi JH, Kim DG, Chung HT, Lee J, Paek SH, et al. (2009) Radiosurgical treatment of vestibular schwannomas in patients with neurofibromatosis type 2: tumor control and hearing preservation. Cancer 115(2): 390398.

58. Sun S, Liu A (2014) Long-term follow-up studies of Gamma Knife surgery for patients with neurofibromatosis Type 2. J Neurosurg 121: 143-149.

59. Mallory GW, Pollock BE, Foote RL, Carlson ML, Driscoll CL, et al. (2014) Stereotactic radiosurgery for neurofibromatosis 2-associated vestibular schwannomas: toward dose optimization for tumor control and functional outcomes. Neurosurgery 74(3): 292-300; discussion 300301.

60. Kruyt IJ, Verheul JB, Hanssens PEJ, Kunst HPM (2018) Gamma Knife radiosurgery for treatment of growing vestibular schwannomas in patients with neurofibromatosis Type 2: A matched cohort study with sporadic vestibular schwannomas. J Neurosurg 128(1): 49-59.

61. Shinya Y, Hasegawa H, Shin M, Sugiyama T, Kawashima M, et al. (2019) Long-Term Outcomes of Stereotactic Radiosurgery for Vestibular Schwannoma Associated with Neurofibromatosis Type 2 in Comparison to Sporadic Schwannoma. Cancers (Basel) 11(10): E1498.

62. Chung LK, Nguyen TP, Sheppard JP, Lagman C, Tenn S, et al. (2018) A Systematic Review of Radiosurgery Versus Surgery for Neurofibromatosis Type 2 Vestibular Schwannomas. World Neurosurg 109: 47-58.

63. Sager O, Dincoglan F, Demiral S, Uysal B, Gamsiz H, et al. (2019) Breathing adapted radiation therapy for leukemia relapse in the breast: A case report. World J Clin Oncol 10(11): 369-374.

ISSN: $2574-1241$

DOI: 10.26717/BJSTR.2020.27.004556

José Antônio Da Silva Neto. Biomed J Sci \& Tech Res

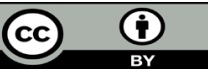

This work is licensed under Creative Commons Attribution 4.0 License

Submission Link: https://biomedres.us/submit-manuscript.php
64. Sager O, Dincoglan F, Uysal B, Demiral S, Gamsiz H, et al. (2018) Evaluation of adaptive radiotherapy (ART) by use of replanning the tumor bed boost with repeated computed tomography (CT) simulation after whole breast irradiation (WBI) for breast cancer patients having clinically evident seroma. Jpn J Radiol 36(6): 401-406.

65. Demiral S, Sager O, Dincoglan F, Uysal B, Gamsiz H, et al. (2017) Dosimetric Evaluation of Breathing-Adapted Radiotherapy for RightSided Breast Cancer. Canc Therapy \& Oncol Int J 7(3): 555713.

66. Sager O, Dincoglan F, Uysal B, Demiral S, Gamsiz H, et al. (2017) Splenic Irradiation: A Concise Review of the Literature. J App Hem Bl Tran 1(1): 101.

67. Sager 0, Beyzadeoglu M, Dincoglan F, Demiral S, Uysal B, et al. (2015) Adaptive splenic radiotherapy for symptomatic splenomegaly management in myeloproliferative disorders. Tumori 101(1): 84-90.

68. Dincoglan F, Beyzadeoglu M, Sager O, Oysul K, Kahya YE, et al. (2013) Dosimetric evaluation of critical organs at risk in mastectomized leftsided breast cancer radiotherapy using breath-hold technique. Tumori 99(1): 76-82.

69. Sager O, Beyzadeoglu M, Dinçoğlan F, Oysul K, Kahya YE, et al. (2012) The Role of Active Breathing Control-Moderate Deep Inspiration BreathHold (ABC-mDIBH) Usage in non-Mastectomized Left-sided Breast Cancer Radiotherapy: A Dosimetric Evaluation. UHOD-Uluslararasi Hematoloji-Onkoloji Dergisi 22(3): 147-155.

70. Uysal B, Beyzadeoğlu M, Sager O, Dinçoğlan F, Demiral S, et al. (2013) Dosimetric evaluation of intensity modulated radiotherapy and 4-field 3-d conformal radiotherapy in prostate cancer treatment. Balkan Med J 30(1): 54-57.

71. Sager O, Beyzadeoglu M, Dincoglan F, Oysul K, Kahya YE, et al. (2012) Evaluation of active breathing control-moderate deep inspiration breath-hold in definitive non-small cell lung cancer radiotherapy. Neoplasma 59(3): 333-340.

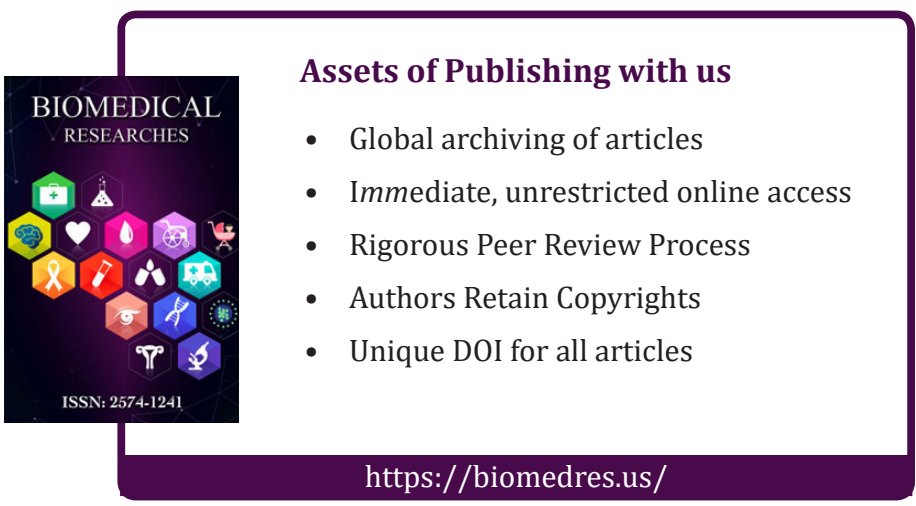

